\title{
Hinduisasi Di Kawasan Megalitik Gunung Slamet
}

\section{Priyatno Hadi Sulistyarto}

Keywords: tradition, culture, megalithic, mountain, beliefs

\section{How to Cite:}

Sulistyarto, P. H. (2003). Hinduisasi Di Kawasan Megalitik Gunung Slamet. Berkala Arkeologi, 23(2), 15-23. https:// doi.org/10.30883/jba.v23i2.872

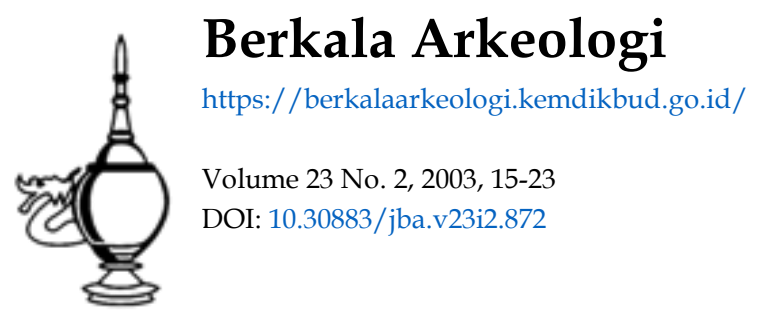

\section{c) (i) (5)}

This work is licensed under a Creative Commons Attribution-NonCommercial-ShareAlike 4.0 International License. 


\section{HINDUISASI DI KAWASAN MEGALITIK GUNUNG SLAMET}

\section{Priyatno Hadi S.}

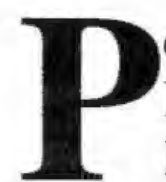

endahuluan

Kebudayaan megalitik yang berkembang pada akhir masa prasejarah di Indonesia adalah suatu kebudayaan yang mempunyai kepercayaan terhadap kekuatan roh nenek moyang. Konsep kepercayaan tersebut melahirkan tradisi mendirikan bangunan-bangunan monumental, yang dibuat dari batu sebagai tempat melakukan kegiatan ritual sebagai pemujaan terhadap roh nenek moyang. Monumen-monumen itu kemudian menjadi ciri utama dan bukti keberadaan kebudayaan megalitik. Kronologi kehidupan manusia pada akhir masa prasejarah tersebut berbatasan langsung dengan masa sejarah, pada saat datangnya kebudayaan India yang membawa pengaruh agama Hindu/Buda atau dimulainya kebudayaan Indonesia klasik. Indonesia sebagai negara dengan wilayahnya yang berbentuk kepulauan memiliki latar belakang kebudayaan yang beragam sehingga mengakibatkan kedatangan pengaruh budaya dari luar membentuk persentuhan budaya yang beragam pula. Bentuk persentuhan kebudayaan India dan Kebudayaan Indonesia berupa akulturasi yang membentuk kebudayaan baru, yaitu kebudayaan Indonesia-Hindu/Buda. Namun demikian bentuk wilayah kepulauan tersebut juga mengakibatkan tidak semua wilayah tersentuh oleh pengaruh budaya dari luar, sehingga kebudayaan asli masih berlanjut terus.

Kebudayaan asli di kepulauan Indonesia pada saat menerima pengaruh kebudayaan Hindu/Buda pada umumnya digambarkan dengan taraf kehidupan masyarakat yang memiliki matapencaharian hidup bercocok tanam. Selain itu, digambarkan pula bahwa masyarakat pada waktu itu telah mengenal navigasi, astronomi, tuang perunggu-besi, pembuatan anyaman, pembuatan gerabah, ukiran kayu, dan pendirian monumen megalitik, serta memeluk kepercayaan animistis (Sulaiman, 1975). Gambaran kehidupan manusia pada akhir masa prasejarah di Indonesia memberikan banyak fenomena budaya yang menarik pada saat menerima sentuhan pengaruh budaya dari luar. Makalah ini berusaha membahas persentuhan antara kebudayaan megalitik dan kebudayaan HinduBuda di kawasan Gunung Slamet.

Tinggalan kebudayaan megalitik di kawasan Gunung Slamet ditemukan di 70 situs yang lokasinya tersebar di seluruh lereng. Kondisi geografis Gunung 
Slamet memiliki morfologi alam yang berbeda dengan daerah dataran di sekitarnya, lereng-lerengnya seolah menjadi batas sehingga membentuk satu kesatuan ruang yang mengakibatkan kawasan itu menjadi bersifat khusus. Demikian pula dengan kebudayaan yang berkembang di kawasan itu, keberadaan situs-situs megalitik di Gunung Slamet merupakan suatu petunjuk bahwa pada masanya kebudayaan megalitik telah berkembang luas dan dianut oleh masyarakat yang bermukim di Gunung Slamet. Selain situs-situs megalitik, di Gunung Slamet juga banyak ditemukan situs-situs dari masa klasik yang persebarannya merata di seluruh kawasan gunung. Bahkan ada beberapa lokasi situs yang menunjukkan campuran dari kedua budaya. Makalah ini berusaha memberikan gambaran fenomena budaya yang terjadi pada kebudayaan megalitik dengan datangnya pengaruh budaya Hindu-Budha di kawasan Gunung Slamet melalui tinggalan arkeologis.

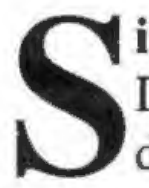

\section{itus-situs megalitik di Gunung Slamet}

Data arkeologi di kawasan Gunung Slamet diperoleh melalui survei yang dilakukan oleh Balai Arkeologi Yogyakarta dengan sasaran bangunanbangunan megalitik. Hasil survei menemukan 70 situs megalitik yang tersebar di seluruh lereng gunung. Pengumpulan data dimaksudkan untuk memperoleh deskripsi tentang data fisik bangunan megalitik dan data lokasi situs. Pengumpulan data dilakukan dengan alat GPS (Global Positioning System), altimeter dan peta topografi skala 1:50.000.

Situs-situs megalitik di Kawasan Gunung Slamet tersebar ke dalam empat bagian lereng sesuai dengan arah mata angin, yaitu di lereng selatan (Kabupaten Banyumas) sejumlah 19 situs. Lereng timur (Kabupaten Purbalingga) terdapat 20 situs, lereng utara (Kabupaten Pemalang) terdapat 11 situs, sedangkan lereng barat meliputi dua kabupaten, yaitu Kabupaten Tegal 15 situs dan Kabupaten Brebes 5 situs.

Situs-situs megalitik di lereng selatan secara astronomis terletak antara $07^{\circ} 10^{\prime} 9^{\prime \prime}$ - $07^{\circ} 36^{\prime} 49$ LS dan $109^{\circ} 12^{\prime} 16$ - $109^{\circ} 25^{\prime} 54^{\prime \prime}$ BT. Situs-situs tersebut situs berada pada lokasi yang memiliki ketinggian antara $195-760 \mathrm{~m}$ di atas permukaan air laut (dpal). Luas wilayah penelitian $4357 \mathrm{~km}^{2}$, jumlah jarak antar situs $72.58 \mathrm{~km}$, dan rata-rata jarak antar situs $3,82 \mathrm{~km}$. Jenis bangunan megalitik yang ditemukan terdiri dari menhir, bangunan berundak, phalus, batu lumpang, batu altar, arca megalitik, struktur batu, meja batu (dolmen). Di 
wilayah ini terdapat bangunan masa klasik yang berasosiasi dengan obyekobyek megalitik, yaitu batu candi dan yoni.

Situs-situs megalitik di lereng timur secara astronomis terletak antara $07^{\circ} 03^{\prime} 00^{\prime \prime}-7^{\circ} 26^{\prime} 10$ LS dan $109^{\circ} 20^{\prime} 15-109^{\circ} 29^{\prime} 13^{\prime \prime}$ BT. Situs-situs tersebut berada pada tempat berketinggian antara 35 - $710 \mathrm{~m}$ dpal. Luas wilayah penelitian $5168 \mathrm{~km}$, jumlah jarak antar situs $128.5 \mathrm{~km}^{2}$, dan rata-rata jarak antar situs $6.42 \mathrm{~km}$. Jenis bangunan megalitik yang ditemukan terdiri dari menhir, bangunan berundak, phalus, batu lumpang, batu altar, arca megalitik, struktur batu, meja batu (dolmen), batu dakon. Selain itu, terdapat batu berrelief, lingga, dan yoni yang berasosiasi dengan obyek-obyek megalitik.

Situs-situs megalitik di lereng utara secara astronomis terletak antara $07^{\circ} 20^{\prime} 11^{\prime \prime}-7^{\circ} 52^{\prime} 30$ LS dan $109^{\circ} 17^{\prime} 30$ - 109 $40^{\prime} 30^{\prime \prime}$ BT. Situs-situs tersebut berada pada lokasi ketinggian antara 340 - $875 \mathrm{~m}$ dpal. Luas wilayah penelitian $499.12 \mathrm{~km}^{2}$, jumlah jarak antar situs $46 \mathrm{~km}$, dan rata-rata jarak antar situs 4.19 $\mathrm{km}$. Jenis bangunan megalitik yang ditemukan terdiri dari menhir, phalus, batu lumpang, arca megalitik, struktur batu, batu silinder berlubang, dan batu wadah persegi . Selain itu, terdapat lingga yang berasosiasi dengan obyek-obyek megalitik.

Situs-situs megalitik di lereng barat secara astronomis terletak antara $07^{\circ} 03^{\prime} 11^{\prime \prime}-7^{\circ} 15^{\prime} 30$ LS dan $109^{\circ} 17^{\prime} 30$ - 109 $40^{\prime} 30^{\prime \prime}$ BT. Situs-situs tersebut berada pada lokasi ketinggian antara $125-1010 \mathrm{~m}$ dpal. Luas wilayah penelitian $8088.36 \mathrm{~km}$, jumlah jarak antar situs $113.8 \mathrm{~km}^{2}$, dan rata-rata jarak antar situs $5.69 \mathrm{~km}$. Jenis bangunan megalitik yang ditemukan terdiri dari menhir, punden berundak, meja batu (dolmen), batu dakon, batu lumpang, phalus, dan arca.

\section{T} linggalan Arkeologi Klasik di Gunung Slamet Informasi mengenai tinggalan arkeologi Klasik di kawasan Gunung Slamet diperoleh dari hasil survei oleh Balai Arkeologi Yogyakarta yang bertema Budaya Marginal Masa Klasik di Jawa Tengah (Tjahjono, 2000). Pemilahan terhadap data hasil survei tersebut diperoleh informasi bahwa di kawasan Gunung Slamet terdapat pula situs-situs Hindu-Buda yang tersebar di seluruh lereng, yaitu sejumlah 27 situs. Lokasi situs menyebar di Kabupaten Banyumas sebanyak 6 situs, di Kabupaten Purbalingga sebanyak 9 situs, di 
Kabupaten Pemalang 4 situs, di Kabupaten Tegal 5 situs, dan di Kabupaten Brebes 3 situs. Jenis-jenis tinggalan budaya klasik di Gunung Slamet terdiri dari lingga, yoni, arca, batu lumpang, phalus, batu candi, dan struktur bata kuno.

\section{Perbandingan Jenis Tinggalan Megalitik dan Klasik di Gunung Slamet}

\begin{tabular}{|c|c|c|c|}
\hline No & Jenis Temuan & Megalitik & Klasik \\
\hline 1 & Menhir & $\mathbf{\square}$ & - \\
\hline 2 & Punden berundak & E & - \\
\hline 3 & Dolmen & 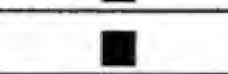 & - \\
\hline 4 & Batu dakon & $\mathbf{0}$ & - \\
\hline 5 & Batu lumpang & - & - \\
\hline 6 & Phalus & 口 & $\mathbf{E}$ \\
\hline 7 & Arca & $\mathbf{D}$ & D \\
\hline 8 & Lingga & - & 国 \\
\hline 9 & Yoni & - & 口 \\
\hline 10 & Batu Candi & - & 口 \\
\hline 11 & Struktur bata kuno & - & E \\
\hline
\end{tabular}

Perbandingan terhadap keragaman temuan antara tinggalan kebudayaan megalitik dan kebudayaan klasik menunjukkan bahwa ada kesamaan jenis tinggalan arkeologi yang dimiliki oleh kedua kebudayaan, yaitu batu lumpang, phalus dan arca. Kesamaan jenis artefak itu apakah menunjukkan pula adanya kesamaan fungsi di antara kedua kebudayaan, atau ada unsur pemanfaatan materi kebudayaan yang satu terhadap kebudayaan lain ? Analisis kontekstual dari ketiga jenis benda ini diharapkan dapat memberukan gambaran mengenai fungsi benda dari kedua kebudayaan tersebut.

\section{R atu Lumpang (stone mortars)}

DPada umumnya batu lumpang di situs-situs megalitik Gunung Slamet dapat dikelompokkan berdasarkan konteks temuan dan karakter lingkungannya. Batu lumpang kelompok pertama merupakan temuan lepas tidak berada satu konteks dengan jenis temuan lain. Namun demikian kelompok batu lumpang ini mempunyai kesamaan biasanya berada pada karakter lingkungan yang sama, yaitu berdekatan dengan air. Batu lumpang dalam kehidupan sehari-hari merupakan komponen penting dalam masyarakat 
agraris, yaitu berfungsi praktis sebagai alat atau wadah menumbuk padi atau biji-bijian lainnya. Dalam konteks megalitik benda ini merupakan benda sakral, yaitu sebagai sarana upacara pemujaan akan kesuburan dalam kehidupan pertanian

Batu lumpang kelompok kedua berada di dalam bangunan punden berundak. Bangunan berdenah persegi yang dipagari oleh struktur batu yang berfungsi sebagai tempat upacara pemujaan. Konteks antara batu lumpang dengan bangunan punden berundak menggambarkan bahwa batu lumpang merupakan benda yang menjadi sarana dalam upacara pemujaan. Hal ini menggambarkan pula bahwa batu lumpang memiliki peranan penting dalam kehidupan masyarakat pendukungnya. Dengan demikian dapat diduga bahwa batu lumpang di Gunung Slamet juga merupakan benda sakral, yang berfungsi sebagai simbol dari suatu pengharapan yang diharapkan akan tercapai melalui upacara pemujaan. Batu lumpang yang berada satu konteks dengan sebuah phalus diletakkan berjajar. Ciri khusus batu lumpang dari situs ini berukuran sangat kecil $(15 \times 10 \times 3 \mathrm{~cm})$. Ukuran lumpang tersebut jelas tidak memungkinkan bahwa batu lumpang itu berfungsi sebagai alat keperluan sehari-hari melainkan lebih untuk suatu simbol.

Batu lumpang yang berfungsi sakral sangat tampak pada konteks temuan antara batu lumpang dan menhir. Menhir dan lumpang diletakkan secara berpasangan posisi menhir didirikan di dalam lubang lumpang dengan posisi tegak menyerupai susunan lingga-yoni (lihat foto). Temuan ini merupakan suatu bukti adanya perkembangan peranan lumpang dari budaya megalitik ke budaya klasik. Susunan lingga-yoni merupakan simbol dari pasangan laki-laki dan wanita. Lingga sebagai simbol dari Dewa Çiwa (pemberi air), sedangkan yoni merupakan simbol dari Dewi Uma. Pasangan antara laki-laki dan wanita diartikan sebagai lambang kesuburan (Bosch: 1961). Berdasarkan pengertian itu dapat dianalogikan bahwa pasangan batu lumpang-menhir atau batu lumpang-phalus juga merupakan suatu simbol dari pasangan laki-laki dan wanita yang melambangkan kesuburan. 


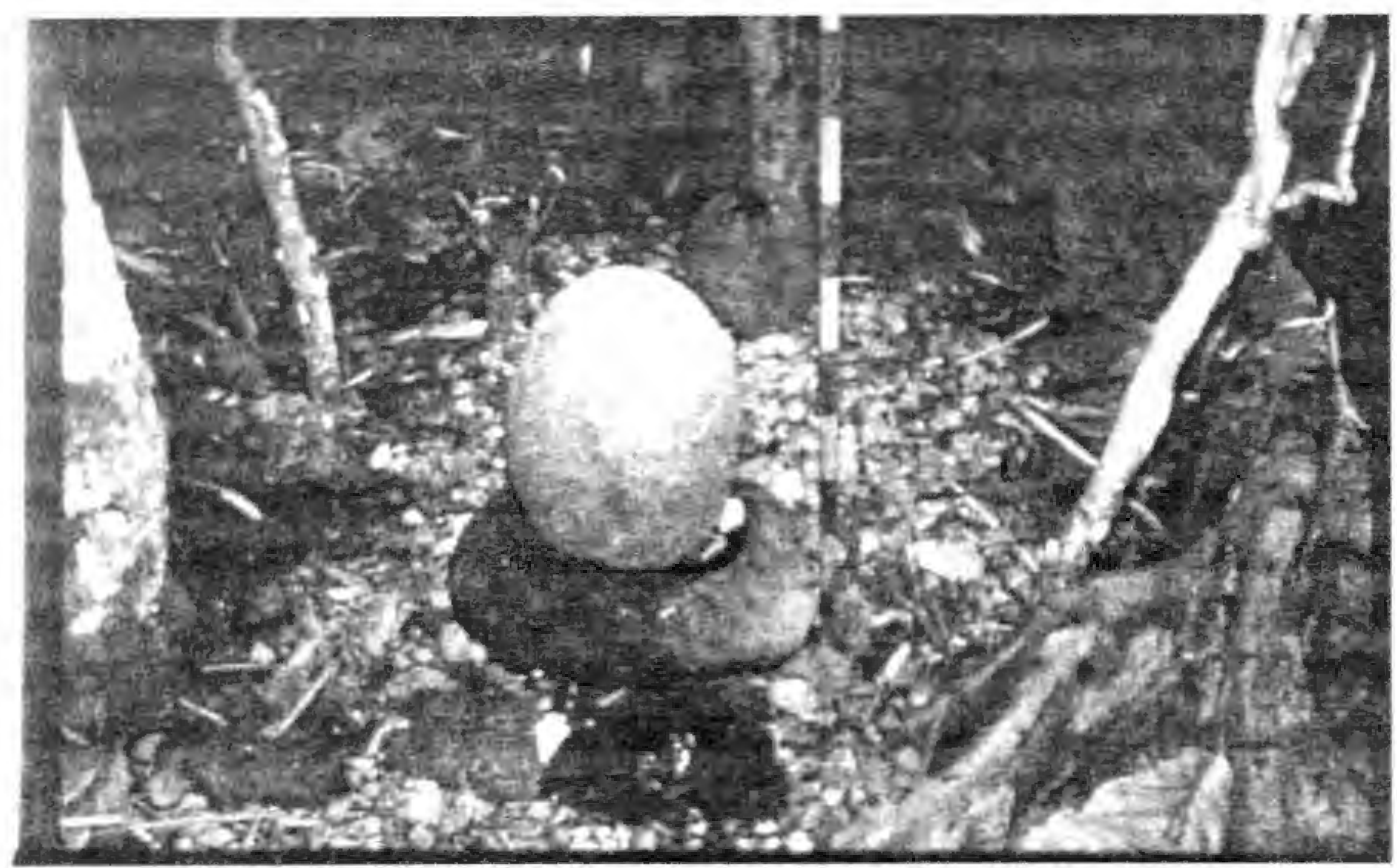

Menhir-Batu Lumpang sebagai embrio Lingga-Yoni

Batu lumpang pada budaya klasik juga memiliki dua fungsi yaitu sebagai alat keperluan sehari-hari untuk wadah menumbuk biji-bijian. Sedangkan dalam fungsi keagamaan disebut dengan istilah kulumpang adalah sebagai obyek utama dalam suatu upacara suci keagamaan, yaitu sebagai simbol dari siklus kehidupan manusia yang berkaitan dengan alam. Lumpang adalah simbol manusia dalam bentuk jasmaniah (susuk kulumpang-lingga) yang disatukan dan diisi dengan unsur rohaniah (kulumpang), kedua benda tersebut adalah benda yang bertujuan untuk keselarasan semesta alam (Kartakusuma, 1996)

\section{Dhalus}

1 Phalus adalah benda peninggalan megalitik yang terbuat dari batu berbentuk lonjong pada salah satu ujungnya dipahatkan bentuk alat kelamin laki-laki. Pada kebudayaan megalitik seringkali ditemukan arca manusia dengan memperlihatkan alat kelamin yang digambarkan secara menonjol. Organ tubuh tersebut dipahatkan secara natural dengan proporsi ukuran yang jauh lebih besar dari organ tubuh lainnya. Phalus tidak lagi digambarkan menempel pada tubuh arca tetapi secara sengaja dibuat sebagai benda lepas untuk menggambarkan alat kelamin laki-laki. Menurut kepercayaan masyarakat megalitik organ tubuh manusia dianggap memiliki kekuatan gaib dan alat kelamin merupakan organ yang paling kuat mengandung kekuatan gaib itu (Sukendar,1985). 
Berdasarkan asumsi bahwa phalus memiliki kekuatan gaib maka dapat diduga bahwa fungsi phalus dalam masyarakat megalitik dikaitkan dengan fungsi alat reproduksi manusia yaitu sebagai lambang kesuburan. Dengan demikian pendirian sebuah phalus menggambarkan suatu harapan agar alam dimana phalus itu didirikan akan menjadi subur. Asumsi bahwa fungsi phalus sebagai lambang kesuburan diperkuat pula dengan konteks temuan lain, yaitu batu lumpang. Batu lumpang adalah komponen penting dalam masyarakat agraris, yaitu berfungsi praktis sebagai alat atau wadah menumbuk padi atau biji-bijian lainnya.

\begin{abstract}
Area
A Arca megalitik di Gunung Slamet memiliki bentuk yang beragam dari bentuk sederhana hingga bentuk yang dinamis. Arca megalitik (di situs Batur Agung) ditemukan dengan konteks temuan, antara lain: menhir, punden berundak, batu lumpang, dan altar. Keletakan arca megalitik di situs ini berada di halaman teratas atau halaman paling sakral. Arca diletakkan berjajar di tepi ruangan di atas lapik yang terbuat dari lempengan batu andesit. Konteks temuan dan keletakan arca menunjukkan bahwa situs tempat ditemukan arca megalitik merupakan situs pemujaan dan arca megalitik berperan sebagai obyek pemujaan. Demikian pula pada kebudayaan klasik arca merupakan perwujudan dari dewa sebagai lambang dari dunia atas sebagai tempat untuk memohon segala pengharapan.
\end{abstract}

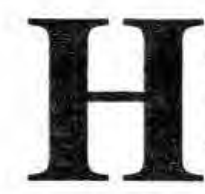

\title{
induisasi di kawasan megalitik Gunung Slamet
}

Sebagaimana telah diketahui bahwa Gunung Slamet merupakan kawasan yang dihuni oleh masyarakat megalitik, yang hidup dari matapencaharian bercocok tanam. Masyarakat yang menganut kepercayaan terhadap roh nenek moyang, yang memiliki tradisi mendirikan bangunanbangunan megalitik sebagai sarana pemujaan. Jumlah dan sebaran situs megalitik di kawasan itu membuktikan bahwa masyarakat pada waktu itu telah menganut kepercayaan dan menjalankan tradisi megalitik secara meluas di seluruh lereng gunung. Masyarakat megalitik di Gunung Slamet sebagai masyarakat yang hidup dari mata pencaharian pertanian tidak bisa dilepaskan dari aspek kesuburan tanah dan ketersediaan sumber air. Upaya untuk menjaga kesuburan tanah dan ketersediaan sumber air dilakukan dengan melakukan kegiatan upacara pemujaan terhadap roh nenek moyang yang dianggap kekuatan menguasai alam. Upacara itu dilakukan dengan memberikan sesaji dan meletakkan sarana-sarana pemujaan di lokasi yang berdekatan dengan 
sumber air. Sarana upacara itu berupa batu lumpang atau phalus. Kedua jenis benda itu sama-sama merupakan simbol kesuburan. Tradisi megalitik yang berhubungan dengan upacara bertujuan untuk kelangsungan pertanian masih berlangsung sampai sekarang, seperti upacara "sedekah gunung" dan "sedekah bumi". Upacara dilakukan dengan memberikan persembahan berupa makanan yang seluruhnya dibuat dari umbi-umbian dan daun pisang sebagai wadahnya. Menurut kepercayaan penduduk setempat, apabila lumpang tersebut berisi penuh dengan air, menandakan tanaman tumbuh subur dan panen berhasil. Apabila guci tersebut hanya setengah berisi air, panen cukup berhasil, akan tetapi bila lumpang tersebut kering, pertanda terjadi kemarau panjang dan panen tidak berhasil.

Kehidupan masyarakat megalitik menjalankan tradisi secara terus menerus hingga datangnya pengaruh kebudayaan Hindu-Buda. Hinduisasi di wilayah ini dilakukan dengan cara memanfaatkan sarana-sarana pemujaan megalitik, antara lain batu lumpang dan phalus. Konsep pemujaan yang digunakan pun masih sama yaitu kesuburan, suatu konsep yang mutlak diperlukan dalam masyarakat pertanian. Proses Hinduisasi tampak pada penggunaan lumpang batu dan phalus secara bersama-sama, yaitu dengan mendirikan phalus atau menhir ke dalam lubang lumpang sehingga menyerupai susunan lingga-yoni. Dengan demikian fungsi phalus atau menhir mewakili keberadaan lingga, sedangkan fungsi lumpang mewakili keberadaan yoni. Lingga dan yoni merupakan benda sebagai simbol dalam agama Hindu. 


\section{KEPUSTAKAAN}

Bosch, F.D.K.. (1961) Guru, Trident, and Spring dalam Selected Studies in Indonesian Arcaheology, (The Hague: Martinus Nijhoff), 155 - 170

Kartakusuma, Richadiana, Obyek Upacara Sima Pada Masyarakat Jawa Kuna Abad IX-X Masehi: Kajian AwaI Tentang Lumpang Batu Berdasarkan Prasasti Panggumulan Dan Prasasti Rukam, dalam Jejak-jejak Budaya II, API Yogyakarta: 1996)

Tjahjono, Baskoro Daru, Budaya Marginal Masa Klasik di Jawa Tengah, Berita Penelitian Arkeologi No. 12, Balai Arkeologi Yogyakarta, 2000 .

Wales, H.G. Quaritch. (1958), The Mountain of God: A Study in Early Region and Kinship. London: Bernard Quaritch Ltd.

Sulaiman, Setyawati. Pictorial Introduction to the Ancient Monuments of Indonesia, The Archaeological Foundation for The Archaeological Institute, Sponsored by Ford Foundation, 1975. 